\title{
Ueber das Lupinenbitter;
}

\author{
vom \\ Professor Cassola \\ in Neapel.
}

Auszug aus der Gazzetta eclettica d. Farmac. Anno III. 83.

Wenn man das Mehl der gemeinen Lupinen (Lupinus termis L.) mit Wasser behandelt, so nimmt dieses einen bittern Geschmack an. Herr Dr. Rivaz wünschle diese biltere Substanz in der Medicin anzuwenden; durch folgendes Verfaluren habe ich sie dargestellt. Ich behandelte zuerst das Lupinenmehl mit kochendem Wasser, aber die darin so reichlich enthaltene albuminöse Subsłanz coagulirte die ganze Flüssigkeit dergestalt, dass sie sich nicht filtriren liess. Ich wandte daher Alkohol von $40^{\circ} \mathrm{B}$. zur Auskochung des Samens an; die abfillrirte Tinctur hinterliess nach Verdampfen eine grünlich-gelbe durchscheinende Masse. Ich löste sie hierauf in reinem Wasser auf, behandelte sie mit Thierkohle und verdunstete sie zur Syrupsconsistenz, worauf sich weisse Körnchen darin absetzten, die indess auch unler der Lupe keine bestimmte Form zeigten; ich verdampfte das Ganze zur Trockne, behandelte den Rüickstand mit heissem Alkolol, und erhielt durch Verdunsten dieser Lösung die bittere Sub$\operatorname{stanz}$, die ich Lupinin nenne.

Das Lupinin ist grünlich-gelb, fest, durchscheinend und briichig wie arabisches Gummi; hygroskopisch; schmeckt sehr bitter. Es löst sich in Wasser in allen Verhältnissen, weniger in Alkoliol von $40^{\circ} \mathrm{B}$, in Aether und in wasserfreiem Alkohol ist es fast unlöslich. Im Feuer schmilzt es wie Wachs. Schwefelsäure verändert seine Farbe nicht merklich; auch die andern Säuren und Kali zeigen keine 
besondere Reactionen damit; durch Salpetersäure wird es nach und nach gelb und zersetzt. Bei der trocknen Destillation giebt es Kohlenwasserstoffgas, Kohlenoxydgas, Kohlensäure, brenzlichtes Oel und eine Spur Ammoniak.

\section{Ueber das Phloridzin, eine neue organische Substanz.}

Die Herren de Konninck und J. S. Stas haben, nach einer kurzen Nachricht im Journ. de Chim. med. (2 Ser. IT. T. 259), in der Rinde des wilden Kirschen -, Pflaumen-, Apfel - und Birnenbaums eine neue organische Substanz gefunden, die sie Phloridzin nennen. Sie ist gelblich - weiss, krystallisirt in kleinen seidenglänzenden Nadeln, schmeckt anfangs bitter, nachher zusammenziehend, ist in Wasser löslich, leichtlöslich in Alkohol und Aether, wirkt nicht auf die Reagenspapiere; löst sich ohne Zersetzung in concentrirter Schwefel- und Salzsäure, und die Auflösung wird nach und nach gelb. Die wässrige Auflösung des Phloridzins wird von essigsaurem Blei reichlich weiss gefällt, das schwefelsaure Eisen wird dadurch braun gefärbt, Kalkwasser, Ammoniak, Brechweinstein und Sublimatlösung aber werden dadurch nicht verändert.

\section{Analyse der Wurzel von Apocynum can- nabinum.}

Die Wurzel dieser Pflanze, welche in Virginien und Canada als Emeticum, Purgans, Sudorificum und Drasticum gebraucht wird, enthält nach John H. Griscom 